\title{
Cognitions and Practices of Iranian ELT Instructors and Content Teachers in Teaching Discipline-Based EAP Courses: A Replication Study
}

\author{
Fatemeh Soleimani \\ MA students at Sheikhbahaee University, Iran \\ e-mail: soleimanif1990@gmail.com
}

\author{
Ahmad Alibabaee \\ Assistant professor at Sheikhbahaee University, Iran \\ e-mail:ahmadalibabaee@gmail.com
}

\begin{abstract}
Although research studies on methodological issues of English for General Purposes are abundant in the literature, they are still one of the less explored areas of research in English for Academic Purposes, especially with respect to teachers' cognitions and practices. Also, lack of collaboration between ELT instructors and content teachers in teaching discipline-based EAP courses has resulted in noticeable inconsistencies in the two groups' instructions. The present study was an extension of Atai and Fatahi-Majd (2014) and explored the cognitions and practices within and across six Iranian ELT instructors and six content teachers regarding their translation-based, form focused, feedback and vocabulary teaching activities. Each participant was observed for six sessions. Field note taking and semistructured interviews were also done with the two groups of teachers so as to delve into the cognitions underlying their actual practices. The general findings supported Atai and Fatahi (2014) in all the areas under investigation where there were within group inconsistences and across-group discrepancies within and between the two groups of teachers respectively with content teachers being much more inconsistent than ELT instructors in terms of their practices and cognitions. The findings of the study have implications for renewing the current practices of ELT instructors and content teachers teaching discipline-based EAP courses worldwide.
\end{abstract}

Keywords: Content and ELT instructors; Feedback; Form-focused activities; Teachers' practices and cognitions; Translation-based activities 


\section{Introduction}

Teaching English for academic purposes (EAP), in which all decisions as to content and method are based on the learners' reasons for learning (Hutchinson \& Waters, 1987), is a language course with a need- oriented approach to TEFL and with a specific methodology as an eminent part (Dudley Evan \& John, 1991; Flowerdew \& Peacock, 2001; Watson Todd, 2001). Despite its significance and accountability, and its highly specific nature, EAP methodology has received partial, or less noticed attention in EAP mainstream. In fact, there seems to be an imbalance in the literature with more attention paid to 'what' than to 'how' of EAP (Watson Todd, 2003). Moreover, compared with the extensive research on techniques and practices in English for general purposes, research on EAP methodology and practices is still scanty (Atai \& Fattahi, 2014). Although the related literature suggests some appropriate techniques and methodological principles and guidelines for EAP teaching, there seems to be exigencies for inspecting the pattern of actual practices as implemented by EAP teachers as well as probing the rationale and cognitions underlying their practices in discipline based EAP courses.

Studies on EAP methodology reveal that scholars have taken two different positions which echo several shifts toward and away from subject specificity in terms of approaches and principles. The first position, the narrow-angled camp, highlights the importance of subject specificity in EAP methodology (Hyland, 2006) and stresses that excessive reliance on the language-centered model of EAP methodology might be fraught with frustration due to the diversity and accountability of target tasks and genres on the part of the EAP students. While stressing the role of genre with the aim of fostering students' genre awareness and discourse knowledge in any EAP context, this position signifies consciousness raising and scaffolding as basic EAP methodologies.

The second position shows an increased interest in a shift away from subject specificity. Hutchinson and Waters (1987), in the wide-angled camp, argued against subject specific teaching and plot EAP on a learner-centered model. Still within the continuum of subject specificity reliance or avoidance, other scholars also have attempted to translate the basic theoretical principles underlying their recommended approach to EAP into practice through enumerating a variety of techniques with regard to EAP methodology including such communicative-oriented practices as role play, simulation and case studies (Huckins, 1988; McDonough, 1984).

Yet, another ideal method for EAP, based on the demands of the target situation and toward subject specificity, can be characterized through the integration of all language skills and inclusion of students' use of cognitive and behavioral styles in persuasive communication (Robinson, 1991). This acclaimed authenticity behind EAP exercise typology relates to students' target needs (Robinson, 1991) as the indicator of methodological differences between EAP and strands of ELT activities. Thus, such courses as TESOL and TEFL are insufficient for EAP programs, since EAP drives its distinctiveness from the specific aims intended to achieve (Scott, 2001). As such, in spite of the surge of scholarly insight and recommendation on EAP methodology, the gap is realized in different academic contexts that offer EAP 
courses with two distinct groups of teachers, ELT instructors and content-specific teachers (e.g., Chen, 2011). These courses, in fact, have long been presented independently either by ELT instructors or by content specific teachers who base the classroom practices on their own deeply held often unexamined cognitions and experiences with little or no cooperation with the other group in terms of methodological and assessment principles (Atai, 2002; Atai \& Nazari, 2011).

As a result of leaving EAP methodology out of picture (Anthony, 2011; Chen, 2011), two trends as related to EAP course implementation have come to forefront. The first trend refers to the superiority of content specific teachers in undertaking EAP courses (e.g., Belcher, 2009; Chen, 2011; Fukui et. al, 2009), in which knowledge about the field can take precedence over knowledge about language learning and teaching (Anthony, 2011). Accordingly, subject teachers are generally perceived as better candidates for teaching EAP courses; hence, ELT instructors find themselves out of contention for tenure-track positions in handling such courses. This situation gets worse when lack of content specific knowledge in EAP courses, despite being just as a carrier of content, might add to the daunting aspects of EAP approach on the part of ELT instructors with the risk of providing blatantly wrong feedback (Belcher, 2009). This trend stresses the question of EAP practitioners' subject knowledge dilemma (Sifakis, 2003; Wu \& Badger, 2009). Therefore, the proponents of this trend point to ELT instructors' lack of essential knowledge of the content that may lead to their failure in expressing the ideas that contribute to understanding the intended learning outcome (Robinson, 1991).

In contrast, the second trend points to ELT instructors' responsibility to take care of such courses due to its inseparability from their field of specializations and the goals that EAP courses are intended to pursue (Anthony, 2011; Hutchison \& Waters, 1987; Scott-Berret, 1989). This trend has largely been promoted by two major concerns, first being that EAP has developed its own unique principles regarding teaching methodology and assessment principles (Anthony, 2011). The second concern points to the inseparability of EAP enterprise from both TEFL and ELT instructors' career, considering the reasonable awareness and cognitions every ELT instructor has adequately developed of the identified principles (McDonough, 2005; Watson Todd, 2003). Within these two trends, the focus of studies have mostly been on the practices implemented by the teachers and stressed the lack of specialist knowledge on the part of ELT instructors (e.g., Scott-Barrett, 1989; White, 1981) and left the rationale and cognitions underlying EAP teachers' actual practices and methodological principles untouched.

With the increase of scholarly research on the role of teachers' unobservable cognitive dimensions of teaching on the effectiveness of ELT courses, teacher cognition has been approached as a broad area encompassing teachers' teaching decision, mental lives and conception of teaching (Alexander, 2012). In fact, the focus of attention in teacher education and research has immensely changed from studying teachers' observable behaviors towards teachers' cognition, knowledge and beliefs to probe into their instructional practices, pedagogical decisions, and reflections. However, the current literature addresses such issues mostly in EGP (El- 
Okada, 2005; Johnson, 1992) and just marginally in EAP (Atai \& Fattahi-Majd, 2014). In addition, the situation gets worse when considering a lack of disciplinary statues for EAP courses which are offered independently either by ELT departments or by the corresponding content specific departments with, little if any, related cooperation between the two. Hence, little is known about the cognitions and actual practices as well as the methodological principles of these two groups of EAP teachers.

\subsection{Iranian EAP context}

Since 1970s, EAP education in Iran has been part of curriculum for all academic discipline-based courses and turned to an ever growing branch of EFL instruction. This EAP enterprise has rigorously thrived for language specificity in terms of academic disciplines (Atai, 2002), considering the intensive reading comprehension programs and course books (Atai \& Shoja, 2011). The content-specific EAP courses are currently assumed to be implemented at university level and demand students in the corresponding field to pass two or three credit EAP courses, as well as one general English (EGP) course during their undergraduate studies. These EAP courses are assumed to bridge the gap between "learners' general English reading comprehension and their ability to read discipline-based text" (Atai \& Tahririan, 2003, p.4), because reading comprehension development of the content-specific learners have been the main objective set to achieve in any EAP program in Iran. Moreover, the methodological principles in actual implementation of EAP courses in Iran have long been dictated by SAMT (an official organization of university materials development and research affiliated with the Iran's ministry of science, research and technology) which is in charge of undertaking the preparation and compilation of textbook and material development for the curriculum of almost all Iranian EAP context with its rigid and strict format.

In line with what SAMT has prescribed, material production has received due attention with the aim of gearing EFL pedagogy into the learners' needs in target situation within Iranian EAP mainstream education. Unfortunately, such cooperation in material preparation left the classroom implementation level out of account. Hence, it comes as no surprising that, such courses have long been presented independently with little collaboration between the two parties according to their intuitions and experiences (Atai, 2002) at the level of actual practices and methodological principles. Such practices that are usually built on an unproved and intuitive premise lack the verified plausibility with regard to the correspondence between the target needs of the students, curriculum developers' intuition, and the objective of the material (Atai, 2002). Further, the absence of any systematic EAP teacher training procedure (Atai, 2006) as a resource guide at teachers' disposal worsens the confusion. This situation, of course, has been acknowledged to be quite common in EAP teaching of similar contexts where few teachers had formal training in EAP (Alexander, 2007).

Lack of collaboration between two groups of teachers; ELT instructors and contentspecific teachers of the corresponding field, lead to confusion and gap as to understanding of the needs and setting of the objectives in general and actual 
practices in particular (Atai \& Shoja, 2011).In a nationwide exploration of EAP education in Iran, Atai and Tahririan (2003) came up with inefficiency of the so called courses in fostering the students' comprehension. Besides, they also identified a series of major problems in Iranian EAP curriculum, including students' inadequate level of general English proficiency (GEP), a demotivating classroom atmosphere, lack of interactions between teachers and students, and excessive reliance on translation as the dominant reading comprehension technique. Atai (2002) probed the differences in the actual practices in EAP courses run by ELT instructors and content teachers from the students' point of view. He found that content teachers' practices mostly tended to be content-related, whereas ELT instructors' emphasized the utilization of language-related aspects.

More recently, in an in-depth qualitative study, Atai and Fattahi-Majd (2014) explored the actual classroom practices and cognitions of ELT instructors and content teachers teaching EAP reading comprehension in Iran. They found considerable within group inconsistencies among content teachers of EAP courses compared with those observed among ELT instructors. They also pointed out several discrepancies across the two groups of teachers with respect to their practices and cognitions in EAP reading comprehension instruction. Although their findings are revealing and informative, they provided a valuable but partial look at the cognitions underlying teachers' actual practices, focusing just on teaching reading skill and recruiting few participants (three ELT instructors and three content teachers). Therefore, Atai and Fattahi-Majd's (2014) study may remain underrepresented in terms of the current status of EAP in other national universities in Iran and other untapped aspects of L2 methodological issues concerning teaching grammar, and vocabulary and providing corrective feedback in EAP courses.

All in all, the new inception of teacher mental lives and the scarcity of research in EAP methodological issues highlight the need for more research of this kind in Iranian EAP context where the context, needs and goals are locally and culturally sensitive. Such studies can illuminate teachers' practices and scrutinize the cognitions underlying those instructional practices not only to track the underlying aspect of teachers, but also to arrive at a firm common ground to be able to extrapolate the findings to other context with similar problem. Accordingly, the current study as a replication of Atai and Fattahi-Majd (2014) finds it necessary to bridge the gap and explore the cognition underlying teachers' actual practices in Iranian EAP context further. Taken together, the study was an attempt to seek answers to the following research questions:

1. What are the within group similarities or differences in ELT instructors and content teachers' actual practices and their underlying cognitions in teaching EAP courses?

2. What are the across group similarities and difference between ELT instructors and content teachers' actual practices and their underlying cognitions in teaching EAP courses? 


\section{Research Methodology}

\subsection{The Context}

The study was conducted in a given university in Isfahan, Iran in which EGP and discipline-based EAP courses had long been presented to undergraduate students of Engineering and Medical Sciences. All the EAP courses in the language center were presented by teaching staff including 8 full time and 15 part time ELT teachers and 9 content teachers. Teachers had been screened on the basis of their length of service (years of academic teaching) and a short interview supplemented by a demonstration test with respect to their proficiency level to qualify for teaching the EAP courses. ELT instructors were educated in TEFL and content teacher studied in different branches of engineering and Medical sciences with no formal training in ELT. More than 2000 students had been enrolled in the corresponding EAP courses in the second semester of 2013-2014 academic years. In terms of material preparation in general and textbook in particular, the textbooks, published by SAMT and devoted to the development of students' reading comprehension, were assigned to the teachers. The classes were almost similar in terms of size (about 40 students in each) and students' age (ranged between 18 and 25). It is noteworthy that these two groups of teachers (ELT and content) were deliberately selected in this study so as to scrutinize their practices and cognitions in one specific context. Thus, utmost attempts were made to minimize the contaminating effect of contextual factors. As in other EAP contexts in Iran, this research context is almost similar to that of Atai and Fattahi-Majd (2014) in terms of general administrative policies made to run EAP courses in Iranian academic context.

\subsection{Participants}

The participants of the study comprised of 6 ELT instructors and 6 Content teachers teaching discipline based EAP courses to undergraduate students of Engineering, Medicine and their sub-branches in the same context and the same disciplines. These courses were selected assuming some common points on the part of the learners; the same level of proficiency based on their scores on the final test of a two credit course called English for general purposes (EGP). The researchers of the study did their best to consider a series of important criteria (almost the same as those of Atai \& Fattahi-Majd, 2014) in the selection of these teachers, including the disciplines and the academic contexts in which the teachers taught. All of the participants (1 male and 5 female ELT instructors; 5 male and 1 female content teachers) were Iranian and Native speakers of Farsi with master or Ph.D degrees. Their teaching experiences were between 4 and 20 for ELT instructors and 4 and 18 years for content teachers in Iranian mainstream EAP educational system. In Iran content teachers, reasonably proficient enough in English, are usually asked to take the responsibility of teaching EAP courses. Seemingly, this situation gets root from the reluctance of ELT teachers in terms of teaching EAP courses for technical fields like medicine and engineering due to their highly specific content knowledge requirement (Atai, 2002). To observe ethical considerations, the teachers' consent was sought for observation sessions and they were assured about the anonymity of the data as well as the non-evaluative purpose of the study. A brief account of the 
demographic information of the teachers is summarized in Table1 below. Note that numerical labels were considered for reporting the participants' specifications and the results. ELT instructors hereafter called ELT1, ELT2, 3, 4, 5, and 6, and content teacher are called Cont. T1, Cont. T2, 3, 4, 5 and 6.

\section{Table 1}

Participants' demographic information

\begin{tabular}{|c|c|c|c|c|c|c|c|c|}
\hline \multirow[t]{2}{*}{$\begin{array}{l}\text { Participa } \\
\text { nts }\end{array}$} & \multirow[t]{2}{*}{ Gender } & \multirow[t]{2}{*}{$\begin{array}{l}\text { A } \\
\text { ge }\end{array}$} & \multirow[t]{2}{*}{$\begin{array}{l}\text { Field of } \\
\text { specialization }\end{array}$} & \multirow[t]{2}{*}{ Degree } & \multicolumn{2}{|c|}{$\begin{array}{l}\text { years of } \\
\text { academic } \\
\text { teaching }\end{array}$} & \multirow{2}{*}{$\begin{array}{l}\text { Distinguishing } \\
\text { Exposure to } \\
\text { Native context } \\
\text { in language } \\
\text { learning } \\
\end{array}$} & \multirow{2}{*}{$\begin{array}{l}\text { The ESP course } \\
\text { taught: } \\
\text { English for the } \\
\text { Students of. . }\end{array}$} \\
\hline & & & & & General & $\begin{array}{l}\text { EA } \\
P\end{array}$ & & \\
\hline ELT 1 & Female & 31 & TEFL & MA & 5 & 4 & - & Medicine \\
\hline ELT 2 & Female & 35 & TEFL & Ph.D. & 10 & 6 & - & Medicine \\
\hline ELT 3 & Female & 45 & TEFL & Ph.D. & 15 & 8 & - & Nursing \\
\hline ELT 4 & Female & 40 & TEFL & MA & 22 & 20 & - & Midwifery \\
\hline ELT 5 & Female & 27 & TEFL & MA & 4 & 4 & - & Dentistry \\
\hline ELT 6 & Male & 30 & TEFL & Ph.D. & 8 & 4 & - & Health \\
\hline Cont. T 1 & Female & 38 & Nutrition & Ph.D. & - & 10 & - & Nutrition \\
\hline Cont. T 2 & Male & 50 & $\begin{array}{l}\text { Medical } \\
\text { sciences }\end{array}$ & Ph.D. & - & 18 & $\begin{array}{l}\text { Studied in the } \\
\text { UK for } \\
15 \text { years }\end{array}$ & Medicine \\
\hline Cont. T 3 & Male & 45 & $\begin{array}{l}\text { Civil and } \\
\text { architecting }\end{array}$ & Ph.D. & - & 15 & $\begin{array}{l}\text { Studied in } \\
\text { Canada for } \\
10 \text { years }\end{array}$ & $\begin{array}{l}\text { Civil } \\
\text { engineering }\end{array}$ \\
\hline Cont. T 4 & Male & 29 & Electronics & MS & - & 4 & - & $\begin{array}{l}\text { Electronic } \\
\text { engineering }\end{array}$ \\
\hline Cont. T 5 & Male & 38 & $\begin{array}{l}\text { Mechanical } \\
\text { engineering(liqu } \\
\text { ids) }\end{array}$ & MS & - & 10 & $\begin{array}{l}\text { Studied in US } \\
\text { for } 8 \text { years }\end{array}$ & $\begin{array}{l}\text { Mechanical } \\
\text { engineering }\end{array}$ \\
\hline Cont. T 6 & Male & 40 & $\begin{array}{l}\text { Professional } \\
\text { health and care }\end{array}$ & Ph.D. & - & 15 & - & Health \\
\hline
\end{tabular}

\subsection{Instrumentation and data collection procedure}

This study drew on a multi-method data collection procedure (following Atai \& Fattahi's (2014) procedure) in order to increase the dependability and credibility of the data and to comply with the triangulation principle. The present study employs three phases of data collection, each of which is delineated separately below:

\subsubsection{Phase 1: Non-participant Observation}

In order to observe and understand the actual practices EAP teachers implement in their classes, observation sessions were conducted from the beginning of the semester. The researcher attended almost all of the sessions regularly and prior to the presence of the teachers, so as to let the class atmosphere have its natural procedure and prevent any changes in the process of teaching especially with 
teachers' actual practices and interaction during the observation. This was done to nullify the observer paradox effect as argued by Lebov (1970). The observation sessions were conducted over the course of two months and a half. In order to observe the teachers' behaviors, activities and actual instructional practices directly, systematically and accurately, six entire sessions for each teacher, in total, 72 sessions, were observed and audio recorded by one of the researchers. Then, the observer researcher tried to transcribe the recorded data quickly at the end of each session with the purpose of gathering a rather immediate but in depth reference for comparing teachers' practices with those in subsequent sessions. Thus, the transcripts were thoroughly delved into and then, the salient characteristics of teachers' actual practices were exactly summarized. Further, teachers' actual practices were exactly examined to find a distinctive pattern of those recurrent ones so as to probe into teachers' classroom implementation within EAP courses.

\subsubsection{Phase 2: Field note}

The observer researcher was cautious not to restrict her attention to actual practices only, so she paid utmost attention to every subtle feature of the teachers and anticipate novel tasks and practices to accord with McDonough and McDonough (1997) who argue "putting recordings and field notes data together represents a move away from reductionist observation methods towards something one might usefully call elaborative description'" (p.112). Therefore, the observer researcher kept track of the events happened during observations and collected them through field notes. The observer was careful enough in her observations and her field notes, thus, if a new question popped into her mind during observations, it was written down in the field notes to be further explored. This cyclical process in which observation reports and field notes were carefully gathered, described and compared with teachers' practices, in turn, generated further refined questions for the followup interviews. The main purpose of the interview was to make the participants revalidate the researchers' interpretation and pay exact reflection on the cognitions underlying their actual practice implementation, and elicit confirmatory information.

\subsubsection{Phase 3: Semi-structured interview}

The third phase of the data collection was semi-structured interview which was conducted after precisely reviewing the observation reports and field note for each teacher. Based on the actual practices implemented by the teachers, their cognition and conceptualizations in EAP courses, some questions were carefully designed and organized in a semi-structured interview format to determine the teachers' reasons for what they had done during language teaching. It mainly addressed some questions and incorporated topics with regard to the key feature of teachers' cognition and actual practices highlighted in the literature, including, the teachers' cognitions, skills and strategies, the importance and primacy of translation, major challenges in EAP teaching, their preference as to the cooperation with content teachers, their perceptions of students' needs, the consistency of their cognition with those of language center administration expectation and requirements, and finally, the importance of teaching the components of language, namely grammar and vocabulary. The rationale behind using semi- structured interview as argued by 
McDonough and McDonough (1997) was "to be closer to the qualitative paradigm because it allows for richer interaction and more personalized responses" (p.184) and to "allow depth to be achieved by providing the opportunity on the part of the interviewer to probe and expand the interviewee's responses" (Rubin \& Rubin, 2005, p.88). The apropriacy, and content validity of the questions along with the clarity and coverage of the topics were checked by two experts in the field of ESP teacher education and research who were university professors with many years of experience in the field of ESP.

All the interviews were conducted in Farsi (the teachers' L1) to ensure the fluent and easy expression of ideas and with simple wordings to prevent any probable misunderstanding with regard to the special jargon and terminology of EAP teaching and applied linguistics. It was attempted to give equal opportunity to the two groups of teachers and avoid ambiguous or leading questions (Cohen, et. al, 2007). Each interview, lasting at about 45 to 1 hour and a half (an average of 1 hour), was administered on the closing session of observation with each teacher. Further, their actual practices were recounted to them and they were asked for possible reasons. Particularly, the details of their activities were also discussed in order to help them clarify their justifications. Besides, to increase the credibility of the data, the transcripts were also shown to the teachers so as to get them approve the content (Crutcher, 2003).

\subsection{Data analysis}

After collecting the data, several steps were taken to analyze the data qualitatively for the purposes of the study. The data were carefully summarized, reviewed and analyzed with the aim of exploring the teachers' actual practices and then probing into cognitions underlying their actual practices with regard to EAP methodology in discipline-based courses.

Within the phase of data analysis, the data collected through the three protocols, namely observation, field notes and interview with the teachers, were initially transcribed verbatim and coded subsequently. Thus, inductive analysis procedure was adopted and then the data were subjected to content analysis. To do so, the transcribed data were segmented into actual practice units and recurring concepts, categories and themes were identified. After being compared for commonalities running through the practices, those with the utmost similarity were taken to represent the theme and then organized into wider categories. Then, the relationship between them were explored and further explained to arrive at a better understanding of the factors in terms of reaching a distinctive pattern with regard to teachers' actual practices according to the shared themes. Finally, the recurring themes were identified and subsequently labeled. Open coding, axial coding, and selective coding were utilized in this regard (Liamputtong \& Ezzy, 2005; Strauss \& Corbin, 1990).

More specifically, a sum of 4 themes emerged from the observation and field notes collected by the researchers. The identified themes included 'Translation-based practices' (L2 to L1, sentence by sentence, word for word), 'Form-focused 
practices' (analysis of text structure, paragraph organization and discourse markers, etc.), 'Vocabulary' (new words, core, academic, semi-technical, and technical vocabulary) and 'Feedback' (peer, teacher, etc.). It is worth mentioning that, after conducting a comprehensive review; the identified themes were labeled based on the guidelines provided by scholars in the current literature, including discourse and genre organization (Hyland, 2006) and learners' target needs (Hutchinson\& Waters, 1987), as the basic principles and practices of teaching EAP and methodological issues.

In order to check the reliability of the coding, labeling, analyzing, and subsequent validity of data interpretation, the researchers took two measures in the process of data analysis. First, after a two-week time interval, $25 \%$ of the transcribed data were closely reexamined by the second researcher whose familiarity with the research design of the study was ensured. Then, a random cross section of data was juxtaposed against the identified recurrent themes to check the observer researcher's interpretation and accuracy. Ultimately, the results obtained through the given round of analysis led to a high degree of consistency between researchers' analyses. Second, consensus was achieved by the researchers through discussion and supplemented by member checking of the findings (i.e. confirmation of interpretations by participants' feedback)to remove few instances of conflicting interpretations.

\section{Findings}

The results of the analysis of the collected data are presented in Tables 2, 3 and 4. The findings pointed to both "across/within" group similarities and differences in actual practices and underlying cognitions of EAP teachers. Following the lead of Atai \& Fatahi-Majd (2014) in the way of reporting the results for all of the findings in each table, "_" represents the teachers" actual practices and "*" designates teachers' cognition underlying each practice revealed in the interview with the teachers.

\section{Table 2}

Similarities and differences among ELT instructors' actual practices and cognitions

\begin{tabular}{lll}
\hline Practices & similarities & Differences \\
\hline Translation- & -Few translation-based practices & -ELT2 usually worked on the follow \\
based practices & were observed in ELT up translation exercises of the \\
& instructors'practices. & textbook \\
& $*$ The other reading $*$ Due to the interesting nature of \\
& comprehension activities are translation practices for EAP students \\
& much more efficient for \\
& developing students reading \\
& comprehension abilities than \\
Form-based & translation-based activities \\
practices & -Form-based activities (five \\
& teachers) were taken into account \\
& through explicit instruction and a \\
deductive approach to
\end{tabular}


presentation of grammar.

*Considering the age of audiences (i.e., adult) to whom

EAP courses are presented

-Engaging students in the process of leaning through consciousness raising and genre awareness and highlighting comprehension questions.

*In order to develop a repertoire of knowledge and awareness of their discipline-based genre and learning how to rely on the available contextual clues

-Explaining the author's view through the use of modals and some generic pronouns.

*To be able to understand the authors' intention and to answer the questions

Vocabulary -Asking for the meaning of words in context. *Considering the futility of decontextualized words, strategies and knowledge in comprehension

-Analyzing the words into prefix, root, and suffix.

*Gearing the practices to practicality in target situation

- Requiring students to express how the words relate to each other.

*Presenting EAP students with a variety of strategies.

-Raising students' awareness about words that contribute to comprehension the most.

*enabling students to resort to keywords for better comprehension and knowledge of vocabulary
-ELT4 discussed the meaning of technical terms and worked on technical terminology pamphlet supplemented to their textbook.

*To gain the knowledge of frequent technical terms, semi technical and academic words in their discipline as well as their potential use in students' future target setting

- ELT1 attempted to correct errors in the students' pronunciations while reading the texts.

*To avoid misunderstanding resulted from mispronunciation (example: through, / $\theta$ ru:/, thorough, / $\theta$ Arov). 


\begin{tabular}{ll}
\hline Feedback & -No clear error correction and - When students commit an error, \\
systematic feedback provision ELT 2, 3 turned out to peer- \\
was observed among almost all correction. \\
ELT instructors. \\
*Due to the highly complex errors and the practicality of \\
nature of error correction and cooperative group work and peer \\
feedback provision both on correction in EAP classes \\
content and form considering the \\
time constraints and course \\
objectives \\
-Correcting students' errors on an \\
irregular basis. \\
*To avoid frustration and loss of \\
confidence on the part of EAP \\
students by ongoing error \\
correction
\end{tabular}

Table 3

Similarities and differences among content-specific teachers' actual practices and cognitions

\begin{tabular}{|c|c|c|}
\hline Practices & Similarities & Differences \\
\hline $\begin{array}{l}\text { Translation- } \\
\text { based } \\
\text { practices }\end{array}$ & $\begin{array}{l}\text {-Asking students to read the text } \\
\text { sentence by sentence and } \\
\text { checking accurate translation. } \\
\text { * Because of the role of translation } \\
\text { as a criterion for checking } \\
\text { students' comprehension of the } \\
\text { content }\end{array}$ & $\begin{array}{l}\text {-Cont. T2, } 3 \text { asked students just to read } \\
\text { the text aloud but they themselves } \\
\text { translated the paragraphs. } \\
\text { *To correct pronunciation errors } \\
\text { - Cont. T1, } 5 \text { assigned some lectures } \\
\text { and out-of class practices which } \\
\text { required students to extract an abstract } \\
\text { of a recently published article in the } \\
\text { journal related to their corresponding } \\
\text { field. Then, the students were asked to } \\
\text { read the abstract in advance, to } \\
\text { translate and then to present in class. } \\
\text { *To prepare for further academic } \\
\text { studies } \\
\text {-Cont. T6 assigned the same out of- } \\
\text { class practices as those of Cont. T1, } 5 \\
\text { but with a slight difference in their } \\
\text { focus. They were asked to translate the } \\
\text { key words, and write them in the } \\
\text { board, but the presentation was in } \\
\text { English. } \\
\text { *To gain a reasonable vocabulary } \\
\text { knowledge }\end{array}$ \\
\hline
\end{tabular}


Form-based- -No form-based practices were based observed in almost all content practices teachers' classes.

*Because of the impracticality of form-based knowledge for EAP students and their future needs

*Cont. T2, 3, and 4 had no clear idea about the form-based practices and Cont. T6 perceived it as irrelevant practice for EAP courses

Vocabulary -Teaching technical terms in their terminology pamphlet.

*Due to a primary role for technical vocabulary knowledge in comprehension

-A set of vocabulary questions were asked to check their content related meaning.

*To gain a good knowledge of frequent words in the discourse and genre of their discipline

-Translating technical terms before reading the main text and discussing the content-related meanings of the words was noticeable.

*Because of their important role in final exams and students' success

Feedback -No specific practices with the clear focus on error correction were observed.

*Unaware of error correction activities and even unverified understanding about its use
-Cont. T1 often explained the grammar differences which caused meaning change in the text.

*Taking form-based aspects as a means of getting content meaning

-Cont. T1 used visual and graphic organizers for teaching technical terms in their terminology pamphlet and required students to memorize a series of technical terms to present in class.

*To assure better comprehension in further activities and to develop a good academic word knowledge

-Cont.T2, 3 often corrected pronunciation errors with regard to technical terms, formulas and jargon related to content aspect of their corresponding field.

*To avoid misunderstanding of content specific knowledge.

As for the second research question, the across group similarities and differences between ELT instructors and content teachers with regard to cognitions underlying their actual practices and methodological principles were deeply delved into in EAP discipline-based courses they were teaching. The deep analysis of the data pointed to across group similarities and differences with the differences outweighing the 
similarities. The major findings from observation and interview were summarized and illustrated in Table 4.

\section{Table 4}

Similarities and differences in actual practices and cognitions between ELT instructors and content-specific teachers

\begin{tabular}{lll}
\hline Practices & Similarities & Differences \\
\hline Translation- & - & $*$ The difference between the two groups \\
based & in terms of translation-based activities \\
practices & can be attributed to their different views \\
& toward comprehension of EAP texts, \\
& while ELT instructors perceived \\
& translation as a means to an end, content \\
& teachers considered it as an end in itself.
\end{tabular}

\section{Form-based - practices}

Vocabulary

-They both checked the words meaning while implementing a reasonably wide range of practices with different aims in mind.

\begin{abstract}
- Unlike ELT instructors' implementation of form-based practices, Cont. Ts disregarded them in their actual practices. In contrast to content teachers, ELT instructors were aware of the importance of form-based practices.

*ELT instructors' in-depth comments regarding the contribution and significance of form-based practices in discipline-based EAP courses
\end{abstract}

*Unlike ELT instructors, Cont. Ts considered words' meaning, especially technical and content-related as a prerequisite for success in reading comprehension within any EAP course.

*While ELT instructors mentioned a few reasons for their error correction activities (e.g., peer correction), Cont. Ts didn't have anything to say.

\section{Discussion}

A close analysis of the findings in the four areas (translation-based and form-based practices, vocabulary and feedback) provides further evidences for what Atai and Fattahi-Majd (2014) found out about teaching reading comprehension in EAP courses. The findings revealed that the similarities observed among ELT instructors exceeded the observed differences with regard to their actual practices in EAP courses. They, for example, unanimously emphasized the constructive role of formbased practices in EAP classes, such as drawing on words' part of speech, structural clues, and analysis of the text structure, paragraph organization and text discourse 
markers not only for developing reading comprehension, but also for raising students' awareness of discourse specificity and genre organization. It seems that ELT instructors in the current study were well informed in that frequent use of specific words and rhetorical structures in specific academic texts corresponds with EAP's distinctive approach to language teaching (Anthony, 2011). ELT3, for instance, stated: "Developing knowledge and awareness of students' disciplinebased genre might help them in their reading comprehension, academic writing and professional academic speaking skills." Another observed similarity among ELT instructors was that they all presented new words in context while stressing the contextual clues and introduced EAP students with the rules of word formation and analyzed the words into prefix, suffixes.

The reason behind such observations, as revealed in their interviews, can be attributed to their knowledge of theories, approaches, methods and learning needs any language courses intended to set for, as well as their formal ELT education which enhanced their understanding of language needs for EAP courses (Atai \& Fattahi, 2014). For example, ELT 6 commented in the interview that "raising the EAP students' awareness of discipline-based formal properties of English is within the range of EAP teachers' responsibilities as documented in the related literature and as I was trained for in the ESP courses I had in my own MA and Ph.D programs." Also, ELT1 referred to theories and approaches in her ELT education and her subscription to the assumptions of Communicative Language Teaching which urge her what to take into account and emphasis on. This case might support what Alexander (2012) states about teachers with considerable communicative language teaching engagement who aimed to begin EAP teaching continuously revert to pre-service education in terms of what and how to teach.

Moreover, a complex set of sources had shaped such cognitions as probed within interview phase, among which cooperation in material production with SAMT ministry of education, the assumptions based on which EAP course were designed, run and undertaken, formal ELT education, and constant reflection on the feedback they received from students through years of teaching were the most salient ones.

Our analysis of actual practices of the six content teachers indicated that they held divergent dispositions within themselves with the number of within group differences exceeding the similarities. As to the translation-based activities, while Cont. T4 and 5 tended to deal with the content-related meaning of technical terms and new words, Cont. T3, 6 mainly concerned with the content-related sentence by sentence translation of the texts. Particularly, content teachers' comprehensionlabeled questions ended in translation-focused answers either at the word or sentence level. Regarding the role of strategies in reading comprehension development, Cont. T3, 4, and 6 had no idea of strategy enhancement, Cont. T1 had a simple interpretation of the concept because of consulting with ELT instructors, and Cont. T2 and 5 showed some predispositions to position their practice in accordance with the assumption of developing strategies for reading comprehension practices, but when it came to actual practices in classroom, they failed to keep to the strategy 
enhancement assumption for reading comprehension practices favoring more translation-based practices instead.

Similar variations were observed in the content teachers' cognitions underlying their practices. There, in fact, existed a series of practices around which different reasons were articulated by content teachers which made it difficult to identify a consistent pattern. This problem may get roots from the variety of sources that are involved in shaping such cognition. Cont. T3, for instance, referred to his years of studying abroad as an influential factor in shaping his cognitions behind what he actually did in his own EAP courses. Cont. T1 pointed to the experiences she gained from the content-specific courses she taught in the corresponding field as the source of the formation of such a cognition about the importance of translation-based activities and content-related focus on technical words. Cont. T5 referred to his ongoing consultation with one of the ELT staff of the language center as an important factor which directs his cognitions.

Nonetheless, the few cases of similarities in content teachers' practices may represent possible similar cognitions. Such cases dealt with the translation-based activities and vocabulary teaching; especially technical terms as revealed in the interviews. Regarding the former, majority of content teachers tended to assign in and out of class translation-based projects. Cont. T1 and 5 favored presentation of a translated abstract to class and Cont. T6 preferred presentation of an English abstract followed by the Persian equivalents of its key words, guided by different cognitions. While the former aimed at developing academic skills for future academic studies, the latter intended to develop a great knowledge of vocabulary at EAP students' disposal to present their content specific knowledge in oral practices. Cont. T2, and 3 sought accurate Persian equivalents or main idea which acted as criterion against which student comprehension and performance were checked. This priority of translation-based practices in teaching EAP might result from content teachers' pedagogical knowledge (Shulman, 1987) in shaping their cognitions. Another reason could be attributed to the wash back effect where vocabulary comprised a considerable part of final exams in EAP courses. In this regard, Cont. T3 stated that "the administrators' expectations and final exam requirements made me give priority to working on technical words." In the same line, Cont. T4 mentioned that "many constraint factors forced teachers to channel their effort toward the test."

As for the across group differences, the deep analysis of ELT instructors and content teachers' practices pointed to salient contrasts in terms of their actual practices. While ELT teachers in this study motivated EAP students to draw on sentence structure, paragraph organization and discourse markers to compensate for their comprehension deficiencies, the Cont. Ts' actual practices seemed to be sidelined within the realm of EAP courses under the influence of common shibboleth stating that an adequate knowledge of technical vocabulary along with the appropriate translation skill suffice. In fact, content teachers neither implemented strategydevelopment practices suggested by the literature nor followed any other well identified approach instead. On the other hand, ELT instructors' practices integrated strategy development through consciousness raising, learner training and scaffolding 
as well as answering the questions and summarizing the text in academic writing to help learners become fluent and effective readers which have already been recognized in the literature as complementary EAP methodologies (Bernhardt, 2011; Hyland, 2006; Jordan, 1997; Leki\& Carson, 1994). The ELT instructors' underlying cognitions also revealed that they are well informed of the effectiveness of such strategy development techniques, as ELT 4 mentioned: "knowledge and ability of strategy use at EAP students' disposal could be of much help irrespective of the dichotomy of general versus specific labels of the courses presented to them."

Another across group difference identified in the findings relates to the ways the two groups of teachers treated new vocabulary. Cont. Ts excessively checked students' understanding of the technical terms in the corresponding field in the EAP courses. In contrast, for ELT instructors developing vocabulary knowledge took precedence over mere presenting the Persian equivalents of the technical terms. This difference might be due to the two different cognitions the two groups of teachers had developed during years of teaching EAP courses (Atai \& Fattahi-Majd, 2014). As for the ELT instructors, findings of the observation and interview revealed that their cognitions and understanding of EAP methodological principles and actual practices were somewhat directed by wide angle perspective. However, since Cont. Ts' unverified assumptions about the importance of technical terms were developed in their discourse community and guided their practices and shaped their cognitions, it comes as no surprising that their methodological principles and actual practices were neither compatible with narrow-angle perspective nor with the wide-angle perspective.

Further, it should be clearly stated that the magnitude of the influence of institutional concerns such as time constraints, administers' expectation, low level of proficiency on the part of EAP students and outdated material on the formation of teachers' cognitions and its immediate influence on their actual practices should not be overlooked. Further, they exert a noticeable influence on teachers' actual practices in meeting the demands of EAP courses irrespective of the methodological principles or actual practices they would rather to implement.

\section{Conclusions}

Given that teachers' cognitions are to a large extent under the influence of their shared notions and experience in their content -specific community, the present study as a replication of Atai and Fatahi-Majd (2014), aimed to find the likely reflection of these cognitions on the actual practices of ELT instructors and content teachers. Besides, the present study was an attempt to find how EAP teachers' cognitions and actual practices differ in terms of their cognitions and practices when the participants come from different fields of specialization to achieve the same purpose. The findings of the study revealed major differences in the practices and cognitions of the two groups of teachers with the content teachers holding more divergent dispositions within themselves. The findings pointed to a magnitude of sources that influence EAP teachers' cognitions underlying their actual practices to expand our current understanding of EAP methodological principles and their 
contribution to teachers' education in the context of EAP courses in Iran and other Asian countries with the same problem.

This study seems to be a further step toward exploring the methodological principles and actual practices implemented by the two groups of EAP practitioners (i.e. ELT instructors and content teachers) as well as the response to the call by Watson Todd (2003) to find more about the 'How of EAP'. What we found was that the results obtained using different instruments for the two groups are compatible with the idea that in the absence of a systematic EAP teacher education program, cooperation would be the most optimistic condition through which effective partnership (Alexander, 2012; Stewart \& Perry, 2005) and teachers' satisfaction with their practices might be achieved. Thus, in order to contribute to the idea of cooperation, attempts should be made to illuminate the expectation which is required of the two parties. Hence, ELT instructors should take the responsibility of classroom presentation and content teachers should support them by providing comments on specific topics and tasks and struggle by clarifying the concepts that go beyond ELT instructors conceptual knowledge or joining the ESP courses where they are in need of help for technical and content clarification (Anthony, 2011; Atai, 2002).

The findings may also be relevant to EAP context in other Asian educational contexts as a catalyst to enable other teachers to reflect on their cognitions and practices. Given the qualitative nature of the study with its description of EAP methodological issues, findings of the study can provide data-based tasks which are helpful in fostering reflection among EAP teachers. Because, the sensitivity of databased tasks to the context of EAP teaching where its distinctiveness and practicality concerns are different from those of EFL or any other language context with regard to designing language teaching tasks. Approvingly, Borg (1998) contends that taking advantage of teachers' real practices and the rationale behind them could provide an ideal platform for the kind of teacher-oriented inquiry which facilitates selfreflection. In addition, the findings may have some implications for all EAP teachers to verbalize tacitly held cognitions and think consciously about them and to be aware of existing challenges and critical areas in EAP teaching.

However, almost all interpretations deriving from the findings of the current study should be considered under the light of some limitations. The complexity of the concept of cognition made it difficult to have a comprehensive and exhaustive picture of the two groups of teachers' cognitions. Indeed, as Senior (2006) acknowledged, teachers might vary to the extent they can articulate their cognitions and beliefs. Teachers might also not be able to verbalize why they have made a particular decision while teaching somehow due to the changing nature of cognitions. More studies of this kind need to be done in order to track the underlying source of classroom practices while delving into EAP teachers' actual practices and likely influential cognitive construct. Hopefully, studies of this kind could provide a springboard for discussion and an impetus for EAP teachers' critical self-inquiry with regard to cognitions underlying their actual practices in teaching EAP courses. One further line of research is to explore the EAP teachers' knowledge about the features of academic discourse such as knowledge of genre and lexicon in the EAP 
courses they have taught. The comparison of teachers' cognitions with those of students to whom such courses are presented might further illuminate the expectations of the two parties. Probing the effects of educational and institutional constraints on the formation, adaptation, and localization of different cognitions underlying EAP teachers' practices can also be a promising area for investigation.

\section{References}

Alexander, O. (2007). Groping in the dark or turning on the light: Routes into teaching English for academic purposes. In T. Lynch \& J. Northcott (Eds.), Educating legal English specialists and teacher education in EAP: Proceedings of IALS teacher education symposia, 2004 and 2006. Institute for Applied Language Studies, University of Edinburgh.

Alexander, O. (2012). Exploring teacher beliefs in teaching EAP at low proficiency levels. Journal of English for Academic Purposes, 11, 99-111.

Anthony, L. (2011). Products, processes, and practitioners: A critical look at the importance of specificity in ESP. Taiwan International ESP Journal, 3(2), 118.

Atai, M. R. (2002). EAP curriculum planning in Iran: An incoherent educational experience. Special Issue of the Journal of Faculty of Letters and Humanities, Teacher Training University, 9, 17-34.

Atai, M. R. (2006). EAP teacher education: Searching for an effective model integrating content and language teachers' schemes. In Proceedings of PAAL conference. Kangwong National University, Chuncheon, Korea.

Atai, M. R., \& Nazari, O. (2011). Exploring reading comprehension needs of Iranian EAP students of health information management (HIM): A triangulated approach. System, 39, 30-43.

Atai, M. R., \& Shoja, L. (2011). A triangulated study of academic language needs of Iranian students of computer engineering: Are the courses on track? RELC Journal, 43, 305-323.

Atai, M. R., \& Tahririan, M. H. (2003).Assessment of the status of ESP in the current Iranian higher educational system. Proceedings of LSP: Communication, culture and knowledge conference. Guilford, England: University of Surrey.

Atai, M. R., \& Fatahi-Majd, M. (2014).Exploring practices and cognitions of Iranian ELT instructors and subject teachers in teaching EAP reading comprehension.English for Specific Purposes, 33(1), 27-38.

Belcher, D. D. (2009). English for specific purposes: Teaching to perceived needs and imagined futures in worlds of work, practice and everyday life. TESOL Quarterly, 40, 133-156.

Bernhardt, E. B. (2011). Understanding advanced second-language reading. London: Routledge.

Borg, S. (1998). Teachers' pedagogical systems and grammar teaching: A qualitative study. TESOL Quarterly, 32(1), 9-38.

Chen, Y. (2011). The institutional turn and the crisis of ESP pedagogy in Taiwan.Taiwan International ESP Journal, 3(1), 17-30. 
Cohen, L. Manion, L. \& Morrison, K. (2007).Research methods in education, London: Taylor and Francis Group.

Crutcher, R. J. (2003).A computer-aided digital audio recording and encoding system for improving the encoding of verbal reports.Behavior Research Methods, Instruments, \& Computers, 35, 263-268

Dudley-Evans, T., \& St John, M. J. (1998).Developments in English for Specific Purposes: A multi-disciplinary approach. Cambridge, England: Cambridge University Press.

El-Okada, M. (2005).EFL student teachers' cognition about reading instruction.The Reading Matrix, 5, 43-60.

Flowerdew, J., \& Peacock, M. (2001). The EAP curriculum: Issues, methods and challenges. In J. Flowerdew\& M. Peacock (Eds.), Research perspectives on English for academic purposes (pp. 177-194). Cambridge, England: Cambridge University Press.

Fukui, K., Noguchi, J., \& Watanabe, N. (Eds.).(2009). Towards ESP bilingualism. Osaka, Japan: Osaka University Press (in Japanese).

Huckins, T.N. (1988). Achieving Professional Communication relevance in a generalized ESP classroom. In D chamberlain \&R.J.Baumgardener (Ed.), ESP in the classroom: Practice and Evaluation ELT Documents 128 (pp.62-70)

Hutchinson, T., \& Waters, A. (1987). English for Specific Purposes: A learningcentered approach. Cambridge, England: Cambridge University Press.

Hyland, K. (2006). English for Academic Purposes: An advanced resource book. London: Routledge.

Johnson, K. E. (1992). Learning to teach: Instructional actions and decisions of preservice ESL teachers.TESOL Quarterly, 26.3, 507-535.

Jordan, R. (1997). English for Academic Purposes: A guide and resource book for teachers. Cambridge, England: Cambridge University Press.

Labov, W. (1970). The study of language in its social context.Stadium Generale, 23, 30-87.

Leki, I., \& Carson, J. G. (1994).Students' perceptions of EAP writing instruction and writing needs across the disciplines.TESOL Quarterly, 28(1), 81-101.

Liamputtong, P., \& Ezzy, D. (2005). Qualitative research methods. Melbourne: Oxford University Press.

McDonough, J. (1984). ESP in perspective: A practical guide. London: Collins ELT.

McDonough, J. (2005). Perspectives on EAP - an interview with Ken Hyland. English Language Teaching Journal, 59 (1), 57-64.

McDonough, J., \& McDonough, S. (1997). Research methods for language teachers. London: Arnold.

Robinson, P. (1991). ESP today: A practitioner's guide. New York, NY: Prentice Hall.

Rubin, H. J., \& Rubin, I. S. (2005).Qualitative interviewing: The art of hearing data (2nd ed.). Thousand Oaks, CA: Sage.

Scott-Barrett, F. (1989). How technical can you teach? Language Training, 10, 122. 
Scott, M. (2001). "Is an ELT training good enough for EAP?" EL Gazette, September

Senior, R. (2006). The Experience of Language Teaching. New York: Cambridge University Press.

Sifakis, N.C. (2003). Applying the adult education framework to ESP curriculum development: an integrative model. English for specific purposes, 22, 195-211.

Stewart, T., \& Perry, B. (2005). Interdisciplinary team teaching as a model for teacher development. TESL-EJ, 9(2), 1-17.

Strauss, A., \& Corbin, J. (1990). Basics of qualitative research: Grounded theory procedures and techniques. Newbury Park, CA: Sage.

Watson Todd, R. (2003). EAP or TEAP? Journal of English for Academic Purposes, $2,147-156$.

White, G. (1981). The subject specialist and the ESP teacher. In Lexden papers [Essays on teaching English for specific purposes by the staff of the Colchester and Bedford English Study Centres] 2 (pp. 9-14). Oxford, England: Lexden Centre.

Wu, H., \& Badger, R. G. (2009). In a strange and uncharted land: ESP teachers' strategies for dealing with unpredicted problems in subject knowledge during class. English for Specific Purposes, 28, 19-32.

Zuck, L.V. and Zuck, J. (1984). The main idea: specialist and non -specialist judgments. Reading for professional purposes, 25, 146-53. 